\title{
Adenocarcinoma renal metastático em uma Codorna Japonesa (Coturnix coturnix japonica)
}

\author{
Metastatic renal adenocarcinoma in a Japanese Quail (Coturnix coturnix japonica)
}

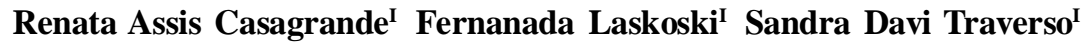 \\ Cristina Takima Kanamura ${ }^{\text {II }}$ Aldo Gava ${ }^{\mathrm{I}^{*}}$
}

\section{RESUMO}

\begin{abstract}
Uma codorna japonesa (Coturnix coturnix japonica), fêmea, adulta com 2 anos apresentou parada de postura, emagrecimento, aumento de volume abdominal $e$ morte. Ao exame macroscópico, observou-se ascite, pulmão esquerdo difusamente esbranquiçado, massas esbranquiçadas, de aproximadamente $1,0 \mathrm{~cm}$ de diâmetro, na região caudal do lobo direito do fígado e na serosa da moela; massas de 0,1 a $0,5 \mathrm{~cm}$ no mesentério e serosa intestinal; e uma massa de $5,0 \times 2,0 \mathrm{~cm}$ na fossa do sinsacro, que acometia $90 \%$ do parênquima renal e estendia-se ao ovário e oviduto. $\mathrm{Na}$ avaliação histopatológica da neoformação renal, observouse proliferação de células epiteliais formando túbulos, que muitas vezes não apresentavam lúmen, sustentados por um estroma fibrovascular escasso associado à necrose multifocal. As células neoplásicas eram cuboidais, núcleos redondos a ovalados, nucléolos evidentes, citoplasma abundante e eosinofílico, pleomorfismo moderado e poucas figuras mitóticas. Metástases foram observadas de forma difusa no ovário, oviduto e pulmão esquerdo; multifocal na serosa do intestino e focal no fígado e camadas muscular e serosa da moela. Na avaliação imuno-histoquímica, as células tumorais foram positivas para a citoqueratina (clones $A E 1+A E 3) e$ negativas para a citoqueratina 5/6, o CD10 e a fosfatase alcalina placentária. De acordo com a localização, achados morfológicos e o perfil imuno-histoquímico, conclui-se que o presente relato trata-se de um adenocarcinoma renal metastático.
\end{abstract}

Palavras-chave: neoplasia renal, ave, patologia, imunohistoquímica.

\section{ABSTRACT}

A 2-year-old Japanese quail (Coturnix coturnix japonica), female, which stopped egg production presented: weight loss, increased abdominal volume, and death. Macroscopically, it was observed: ascites, whitish left lung, whitish masses measuring $1.0 \mathrm{~cm}$ in diameter in the caudal right lobe of the liver and in the gizzard serosa; $0.1-0.5 \mathrm{~cm}$ masses in the mesentery and intestinal serosa; and a $5.0 \times 2.0 \mathrm{~cm}$ mass in synsacral area that encompassed $90 \%$ of the renal parenchyma and part of ovary and oviduct. Histologically, epithelial cells proliferation with formation of tubules, sometimes without lumen supported by mild fibrovascular stroma and multifocal necrosis was observed in the renal mass. The neoplastic cells were cuboidal, with round to oval nuclei, and evident nucleolus, abundant eosinophilic cytoplasm, moderated pleomorphism. Mitotic figures were rare. Metastasis was seen diffuse in ovary, oviduct, left lung, multifocal in intestinal serosa, focal in liver and serosal and muscular layer in gizzard. Immunohistochemically, tumors cells were positive for cytokeratin (clones $A E 1+A E 3$ ) and negative for cytokeratin 5/6, CD10 and placental alkaline phosphatase. According to localization, morphology features and immunohistochemistry evaluation, the present study reports a metastatic renal adenocarcinoma.

Key words: renal neoplasm, bird, pathology, immunohistochemistry.

\section{INTRODUÇÃO}

As neoplasias renais são observadas ocasionalmente em aves selvagens de vida livre e de cativeiro (LATIMER, 1994), especialmente em Periquitos-australianos (Melopsittacus undulatus) (NEUMANN \& KUMMERFELD, 1983; REECE, 1992), não sendo comumente observada em aves domésticas (REECE, 1997).

'Departamento de Medicina Veterinária, Centro de Ciências Agroveterinárias (CAV), Universidade do Estado de Santa Catarina (UDESC), Av. Luiz de Camões, 2090, 88520-000, Lages, SC, Brasil. E-mail: a2ag@ cav.udesc.br *Autor para correspondência.

"Laboratório de Imuno-histoquímica, Serviço de Patologia, Instituto Adolfo Lutz, São Paulo, SP, Brasil. 
O adenocarcinoma é considerado a neoplasia renal vista com maior frequência nas aves (LATIMER, 1994). Os rins afetados apresentam grandes massas multilobuladas e pálidas ou acinzentadas, geralmente unilaterais (HUBBARD \& FLETCHER, 1983; LATIMER, 1994). As massas podem se infiltrar em músculos e ossos adjacentes estendendo-se até o canal medular (LATIMER, 1994), as metástases para outros órgãos podem ocorrer, mas são incomuns (HUBBARD \& FLETCHER, 1983; HOWERTHet al., 1986; LATIMER, et al., 1996). Em galinhas, essa neoplasia ocorre geralmente como sequela da infecção pelo vírus da leucose aviária (PAYNE \& FADLY, 1997).

O objetivo deste relato é descrever o primeiro caso de adenocarcinoma renal metastático em uma codorna japonesa (Coturnix coturnix japonica).

\section{MATERIAL E MÉTODOS}

Uma codorna japonesa (Coturnix coturnix japonica), fêmea, adulta com 2 anos foi encaminhada para necropsia. Fragmentos de todos os órgãos foram fixados em formalina tamponada a $10 \%$ por 24 horas, processadas rotineiramente para exame histológico e coradas pela técnica Hematoxilina-Eosina. Fragmentos da neoformação renal, incluídos em parafina, foram encaminhados ao Laboratório de Imuno-histoquímica do Serviço de Patologia do Instituto Adolfo Lutz de São Paulo.

Após a desparafinização, as lâminas foram submetidas à recuperação antigênica por calor úmido sob pressão em tampão citrato $10 \mathrm{mM}$ (pH 6,0), seguido do bloqueio da peroxidase endógena com água oxigenada a $6 \%$ (20 volumes). A primeira etapa da reação consistiu na incubação dos anticorpos primários. Para o presente estudo, utilizou-se CD10 (clone 56C6, Diagnostic Biosystems, USA, diluição 1:200), Citoqueratina 5/6 (clones D5/16B4, Dako Cytomation, USA, diluição 1:200), Citoqueratina (clones AE1+AE3, Dako Cytomation, diluição 1:2000) e fosfatase alcalina placentária (policlonal, Dako Cytomation, diluição 1:4000). Prosseguiu-se, então, para as etapas de incubação com anticorpo secundário biotinilado genérico (anti-imunoglobulinas de coelho, camundongo e cabra) e, em seguida, com o complexo estreptavidina-biotina-peroxidase (Kit LSAB ${ }^{\circledR}$, Dako Cytomation). A revelação da reação imunoenzimática foi obtida através de solução contendo substrato cromogênico (diaminobenzidina, Sigma-Aldrich, USA), sendo, depois, os cortes submetidos a contracoloração com hematoxilina de Harrys. Controles positivos foram incluídos no processamento.

\section{RESULTADOS}

A codorna enviada para necropsia era criada em uma gaiola com mais duas aves da mesma espécie, sendo alimentados com ração comercial específica para codornas e água ad libitum. Essa ave apresentou parada de postura há aproximadamente três meses, emagrecimento e aumento de volume abdominal, no entanto alimentava-se normalmente. O proprietário encontrou-a morta na gaiola.

Ao exame macroscópico, observou-se animal magro e com o abdômen abaulado. Na cavidade celomática, foram observadas massas esbranquiçadas, de aproximadamente $1,0 \mathrm{~cm}$ de diâmetro, na região caudal do lobo direito do fígado e na serosa da moela (Figura 1); massas menores, que variavam de 0,1 a $0,5 \mathrm{~cm}$, no mesentério e serosa intestinal; e uma massa, de $5,0 \mathrm{~cm}$ de comprimento por $2,0 \mathrm{~cm}$ de espessura, na fossa do sinsacro, que acometia $90 \%$ do parênquima renal e estendia-se ao ovário e oviduto (Figura 2). Além das massas, constatou-se aproximadamente $5 \mathrm{ml}$ de líquido seroso livre na cavidade e pulmão esquerdo difusamente esbranquiçado.

$\mathrm{Na}$ avaliação histopatológica da neoformação renal, observou-se proliferação de células epiteliais formando túbulos de diferentes tamanhos, que muitas vezes não apresentavam lúmen (Figura 3), associados à necrose multifocal moderada. Os túbulos eram sustentados, entre eles, por um estroma fibrovascular escasso. As células tubulares neoplásicas eram cuboidais, de núcleos redondos a ovalados, com 1 a 2 nucléolos evidentes, citoplasma abundante e eosinofílico, com pleomorfismo moderado e poucas figuras mitóticas. Metástases de células neoplásicas com as mesmas características histológicas foram observadas de forma difusa no ovário, oviduto e pulmão esquerdo; multifocal na serosa do intestino e focal no fígado e camadas muscular e serosa da moela.

$\mathrm{Na}$ avaliação imuno-histoquímica, a citoqueratina (clones AE1+AE3) foi positiva difusamente no citoplasma das células neoplásicas (Figura 4) e não houve marcação para a citoqueratina 5/6, CD10 e fosfatase alcalina placentária.

\section{DISCUSSÃO E CONCLUSÃO}

O adenocarcinoma renal é a neoplasia do sistema urinário mais observada em aves selvagens de cativeiro e vida livre (LATIMER, 1994). Em Periquitoaustraliano (Melopsittacus undulatus), é considerado um dos tumores mais importantes (VAN TOOR et al., 1984), sendo que em um estudo avaliando 74 dessas aves com tumores abdominais, $47(63,5 \%)$ apresentavam 


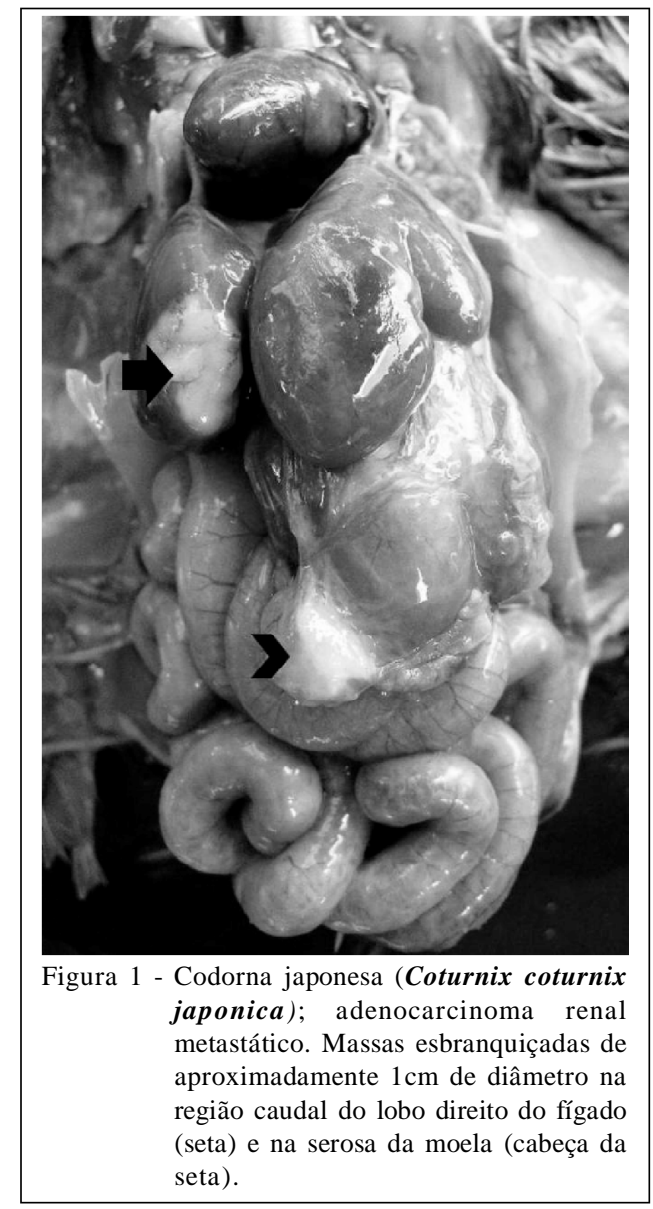

neoplasia renal (NEUMANN \& KUMMERFELD, 1983). Em outro estudo retrospectivo com 157 Periquitosaustralianos com neoplasia, 25 apresentaram adenocarcinoma renal (REECE, 1992). No Brasil, também há uma descrição nesta espécie (GODOY et al., 2009).

Nas demais espécies de aves, este neoplasma é considerado incomum (LATIMER, 1994), mas casos foram relatados em Lóris-arco-íris (Trichoglossus haematodus capistratus) (HUBBARD \& FLETCHER, 1983); em Tetraz (Bonasa umbellus) (HOWERTH et al., 1986); em Pomba-doméstica (Columba livia), em Faisão-coleira (Phasianus colchicus), em Calopsita (Nymphicus hollandicus) (REECE, 1992); em Papagaio-cinzento-africano (Psittacus erithacus erithacus) (LATIMER et al., 1996); e em Águia-real (Aquila chrysaetos) (MIKAELIAN et al., 1998).

Em codorna, há poucas descrições de doenças neoplásicas na literatura. REECE (1992) relatou dois fibroma/fibrossarcoma na pele e um fibrossarcoma no fígado. GORHAM \& OTTINGER (1986) relataram três casos de tumor das células de Sertoli de um total de 33 codornas machos com mais de três anos de idade. Não há descrição de carcinoma renal nesta espécie.
Em aves acometidas por adenocarcinoma renal, os sinais clínicos relatados são dificuldade para empoleirar-se ou locomover-se, paralisia uni ou bilateral (VANTOOR et al., 1984; REECE, 1992; LATIMER, 1994; LATIMER et al., 1996) e abdômen distendido (NEUMANN \& KUMMERFELD, 1983; VAN TOOR et al., 1984). Ocasionalmente, são descritos quadro de gota articular (LATIMER, 1994), emagrecimento e depressão (VANTOOR et al., 1984; MIKAELIAN et al., 1998) ou as aves são encontradas moribundas horas antes da morte (HUBBARD \& FLETCHER, 1983). No presente relato, observou-se apenas parada da postura, emagrecimento e aumento de volume abdominal.

Quanto à localização do tumor, no presente caso, houve o acometimento de todo o parênquima renal com metástases no ovário, oviduto, fígado, pulmão, moela e intestino. As metástases são consideradas incomuns, sendo relatada somente no oviduto (HUBBARD \& FLETCHER, 1983), fígado (HOWERTH et al., 1986) e simultaneamente no pulmão, coração, fígado e intestino (LATIMER et al., 1996).

$\mathrm{Na}$ avaliação imuno-histoquímica, as células neoplásicas eram fortemente positivas para 


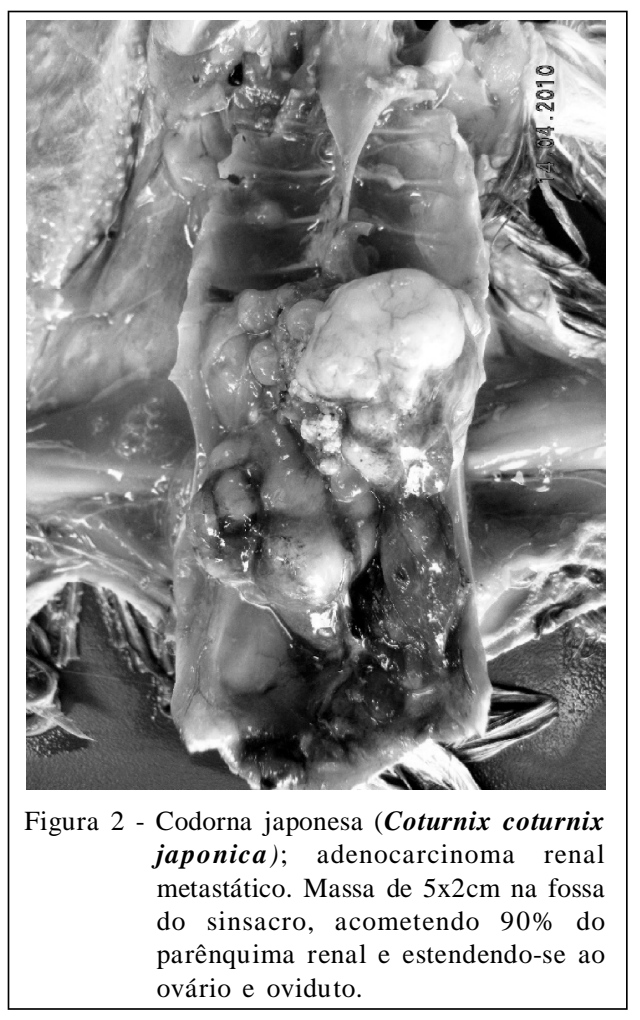

citoqueratina (clones $\mathrm{AE} 1+\mathrm{AE} 3$ ), o que indica a origem epitelial da neoplasia. Este anticorpo identifica a maioria das citoqueratinas, podendo ser utilizado como peça chave para identificação de células de origem epitelial (MOLL et al., 1982). Para a citoqueratina 5/6, não houve marcação. Segundo CURY et al. (2000), os adenocarcinomas são fracamente positivos ou não apresentam marcação para esse anticorpo.

Quanto ao anticorpo CD10, ele marca as células epiteliais tubulares renais, sendo que no

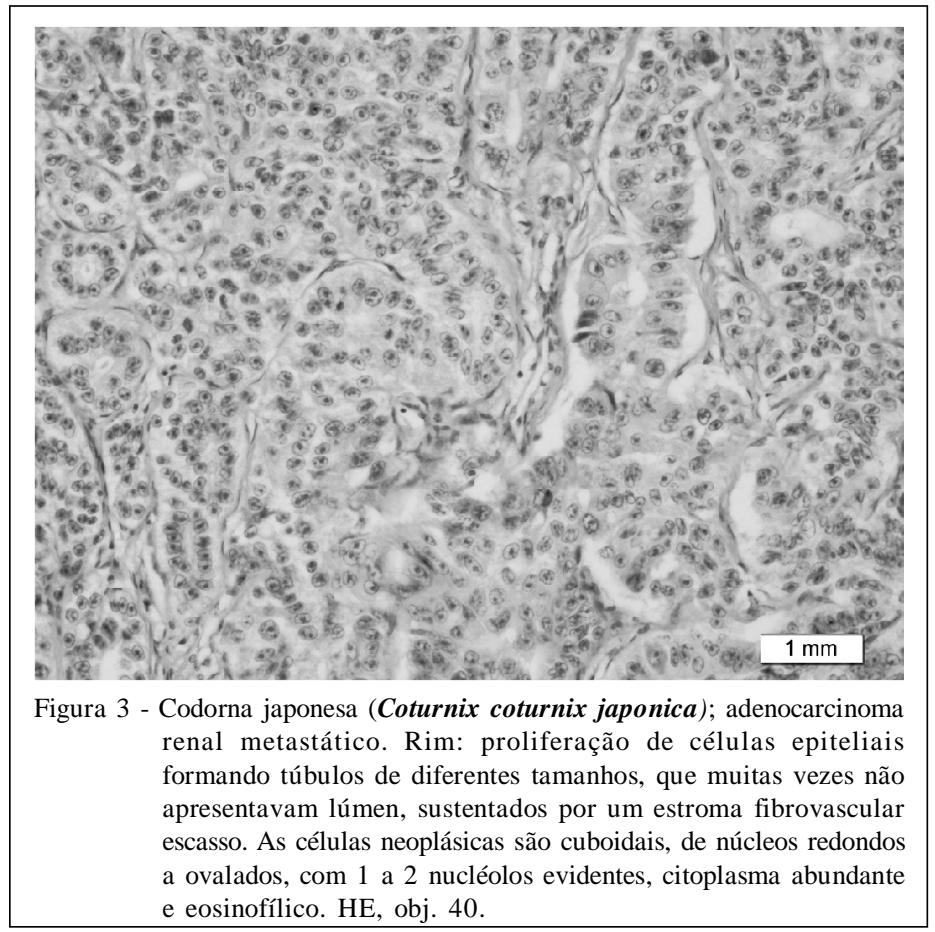

Ciência Rural, v.41, n.11, nov, 2011. 


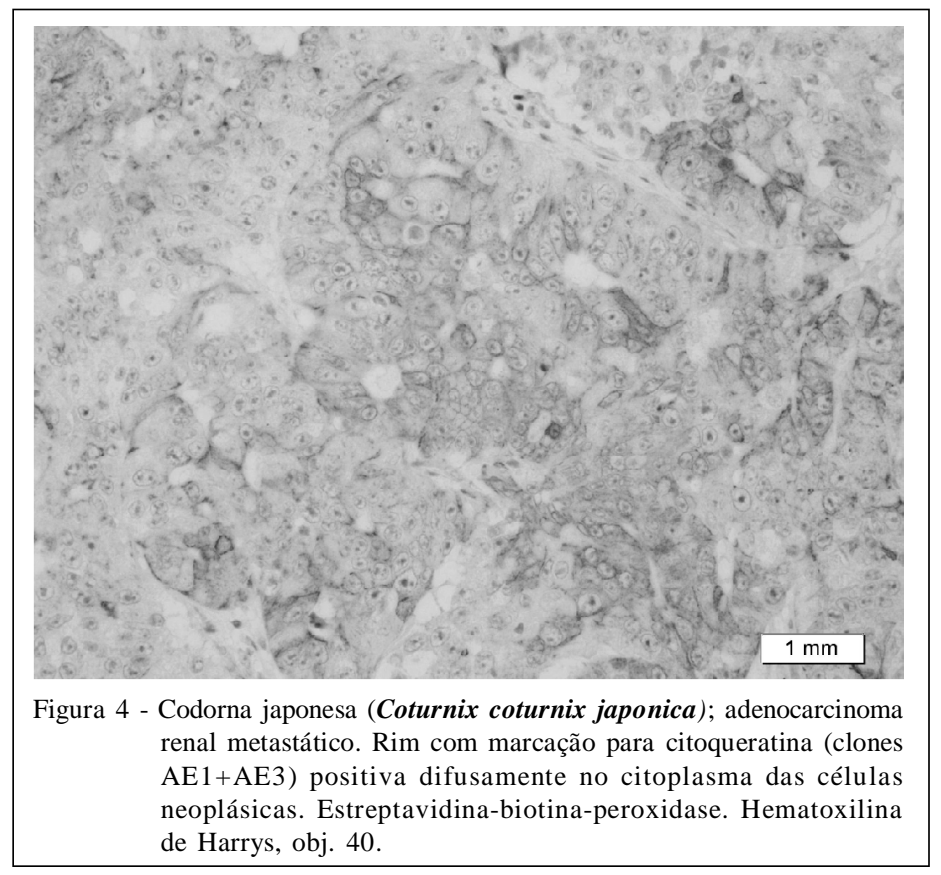

presente estudo não houve marcação. Em um estudo retrospectivo, avaliando 173 carcinomas renais de humanos, apenas 98 (57\%) apresentaram positividade para esse anticorpo (MAZAL et al., 2005).

Neste relato, as células tumorais não apresentaram marcação para o anticorpo fosfatase alcalina placentária. Essa ausência de marcação foi fundamental para confirmar a origem renal das células neoplásicas, uma vez que, nas aves, o rim esquerdo e o ovário estão intimamente próximos, sendo que, assim, macroscopicamente, esses dois tipos de neoplasmas poderiam ser confundidos. Este anticorpo marca células tumorais germinativas malignas, especialmente disgerminoma e os carcinomas embrionários (RABBAN et al., 2010).

De todos os casos de carcinomas renais descritos nas aves, em apenas um houve o emprego do exame imuno-histoquímico para auxiliar no diagnóstico (LATIMER et al., 1996), sendo que nesse foi utilizado apenas uma citoqueratina policlonal para confirmar a origem epitelial da neoplasia.

De acordo com a localização, achados morfológicos e o perfil imuno-histoquímico, concluise que o presente relato trata-se de um adenocarcinoma renal metastático, o qual levou à insuficiência renal e consequente morte do animal.

\section{REFERÊNCIAS}

CURY, P.M. et al. Value of the mesothelium associated antibodies thrombomodulin, cytokeratin $5 / 6$, calretinin, and $\mathrm{CD} 44 \mathrm{H}$ in distinguishing epithelioid pleural mesothelioma from adenocarcinoma metastatic to the pleura. Modern Pathology, v.13, n.2, p.107-112, 2000. Disponível em: <http:// www.nature.com/modpathol/journal/v13/n2/abs/ 3880018a.html>. Acesso em: 20 abr. 2011.

GODOY, S.N. et al. Principais processos neoplásicos encontrados em psitacídeos mantidos em cativeiro. Pesquisa Veterinária Brasileira, v.29, n.6, p.445-451, 2009. Disponível em: <http://www.scielo.br/ scielo.php?script=sci_abstract\&pid=S0100736X2009000600001\&lng= en\&nrm=iso\&tlng=pt>. Acesso em: 18 abr. 2011. doi: 10.1590/S0100-736X2009000600001.

GORHAM, S.L.; OTTINGER, M.A. Sertoli cell tumors in Japanese Quail. Avian Diseases, v.30, n.2, p.337-338, 1986.

HOWERTH, E.W. et al. Neoplasia in free-flying ruffed grouse (Bonasa umbellus). Avian Diseases, v.30, n.1, p.238-240, 1986.

HUBBARD, G.B.; FLETCHER, K.C. Renal carcinoma in a captive Edwards Lory (Trichoglossus haematodus capistratus). Journal of Wildlife Diseases, v.19, n.2, p.160-161, 1983. Disponível em: <http://www.jwildlifedis.org/cgi/reprint/19/2/ 160>. Acesso em: 10 abr. 2011.

LATIMER, K.S. Oncology. In: RITCHIE, B.W. et al. Avian medicine: principles and application. Estados Unidos: Wingers Publisinhg, 1994. p.640-672.

LATIMER, K.S. et al. Metastatic renal carcinoma in an African grey parrot (Psittacus erithacus erithacus). Journal of Veterinary Diagnostic Investigation, v.8, n.2, p.261-264, 1996.

MAZAL, P.R. et al. Expression of aquaporins and PAX-2 compared to CD10 and cytokeratin 7 in renal neoplasms: a tissue microarray study. Modern Pathology, v.18, p.535540, 2005. Disponível em: <http://www.nature.com/modpathol/ 
journal/v18/n4/full/3800320a.html>. Acesso em: 20 abr. 2011. doi:10.1038/modpathol.3800320.

MIKAELIAN, I. et al. Metastatic cholangiocellular carcinoma and renal adenocarcinoma in a golden eagle (Aquila chrysaetos). Avian Pathology, v.27, n.3, p.321-325, 1998. Disponível em: $<\mathrm{h} \mathrm{t} \mathrm{t} \mathrm{p} \mathrm{:} \mathrm{/} \mathrm{/} \mathrm{w} \mathrm{w} \mathrm{w.} \mathrm{in} \mathrm{for} \mathrm{m} \mathrm{a} \mathrm{w} \mathrm{or} \mathrm{ld.} \mathrm{com/s} \mathrm{m} \mathrm{p} \mathrm{p} \mathrm{/}$ content $\sim \mathrm{db}=$ all $\sim$ content $=\mathrm{a} 784670374 \sim$ frm $=$ titlelink $>$. Acesso em: 20 abr. 2011. doi: 10.1080/03079459808419345.

MOLL, R. et al. The catalog of human cytokeratins: patterns of expression in normal epithelia, tumors and cultured cells. Cell, v.31, n.1, p.11-24, 1982. Disponível em: <http:// www.sciencedirect.com/science/article/pii/0092867482904007>. Acesso em: 06 abr. 2011. doi: 10.1016/0092-8674(82)90400-7.

NEUMANN, U.; KUMMERFELD, N. Neoplasms in budgerigars (Melopsittacus undulates): Clinical pathomorphological and serological findings with special consideration of kidney tumors. Avian Pathology, v.12, n.3, p.353-362, 1983. Disponível em: < h t t p : / / w w w. in for m a w or ld . com/ s m p p / content $\sim \mathrm{db}=\mathrm{all} \sim$ content $=\mathrm{a} 789078966 \sim$ frm $=$ titlelink $>$. Acesso em: 05 abr. 2011. doi: 10.1080/03079458308436178.
PAYNE, L.N.; FADLY, A.M. Leukosis/sarcoma group. In CALNEK, B.W. et al. Diseases of poultry. 10.ed. Estados Unidos: Iowa State University, 1997. p.414-466.

RABBAN, J.T. et al. Immunohistology of the female genital tract. In: DABBS, D.J. Diagnostic immunohistochemistry. 3.ed. Estados Unidos: Saunders Elsevier, 2010. p.690-762.

REECE, R.L. Observations on naturally occurring neoplasms in birds in the state of Victoria, Australia. Avian Pathology, v.21, n.1, p.3-32, 1992. Disponível em: <http://www.informaworld.com/ smpp/content $\sim \mathrm{db}=\mathrm{all} \sim \mathrm{content}=\mathrm{a} 784688632 \sim \mathrm{frm}=$ titlelink $>$. Acesso em: 05 abr. 2011. doi: 10.1080/03079459208418815.

REECE, R.L. Tumors of unknown etiology. In: CALNEK, B.W. et al. Diseases of poultry. 10.ed. Estados Unidos: Iowa State University, 1997. p.489-510.

VAN TOOR, A.J. et al. Adenocarcinoma of the kidney in two budgerigars. Avian Pathology, v.13, n.2, p.145-150, 1984. Disponível em: <http://www.informaworld.com/smpp/ content $\sim \mathrm{db}=\mathrm{all} \sim \mathrm{content}=\mathrm{a} 784689304 \sim \mathrm{frm}=$ titlelink $>$ Acesso em: 05 abr. 2011. doi: 10.1080/03079458408418519. 